\title{
Model of Overall Energy Consumption Fairness Proportion Achievable in MANET Using Location- Aware Transmission for Ubicomp.
}

\author{
M. Kaleem GALAMALI, Assoc. Prof Nawaz MOHAMUDALLY
}

\begin{abstract}
Managing energy consumption in ubicomp is a serious topic of research. MANET transmission may help in energy containment in ubicomp [57]. Location-aware transmission can enhance this method for energy containment. It is assumed that in a MANET for ubicomp, nodes present will work in an automated collective fashion to achieve transmission, thereby sharing the workload. It is a conception that for sharing of workload is achieved equitably among all nodes present and hence energy consumption is reduced for each contributing node with increasing node density.
\end{abstract}

In situations of cooperation, it remains important for each cooperating node to gauge what is the degree of effort it is providing, in forms of metric and trends achievable, presented in previous research [19-21] which is referenced against sender node's effort. Another set of metrics for gauging Fairness compared to an assumed equitable energy amount reached if the total energy consumed for a CBR transmission is divided equally among all nodes present in a topography, is also possible. A first metric in this direction, presented in this paper, is ECFP, along with its corresponding trends over varying node densities.

This paper adds up to the area of modelling in ubicomp for designers to better provision for resources and architecture needs. This paper is a follow-up of previous research [1-21].

Key terms: Ubicomp- Ubiquitous Computing, MAUCMobile and Ubiquitous Computing, ECR- Energy Consumption Ratio, Min_R- Minimum Ratio, Max_RMaximum Ratio, OFR- Overall Fairness Ratio, MANETMobile Adhoc Network, BFEA- Basic Fairness Energy Amount, ECFP- Energy Consumption Fairness Proportion, CBR- Constant Bit Rate.

M. Kaleem GALAMALI,

University of Technology Mauritius (student)

Mauritius

Assoc. Prof Nawaz Mohamudally

University of Technology Mauritius, Mauritius

\section{Introduction}

MANET transmission remains a considerable factor affecting energy consumption in MAUC [21], whereby workload is distributed among nodes in MANET routes to achieve cooperative and complete transmission till receiver. Since, the situation is cooperation here, the first conception is that the workload may be distributed equitably among all nodes present. This workload would be assumed to be decreasing if the topography has greater number of nodes. This conception remains an assumption even if mostly, it will not be achieved as only nodes concerned in MANET routes will be spending energy. The concept of equitable energy consumption distribution may not apply for short duration CBR where only certain nodes might have been used. However, as CBR durations tend to increase significantly, and MANET topologies experience high volatility, more and more nodes in the topography may be concerned and hence this "equitable distribution" of energy needs become relevant for study.

Previously defined metrics ECR [18], Min_R [19], Max_R [20] and OFR [21] give indication of energy consumption gauged against sender's effort only. One big limitation of this method of measurement remains that overall contribution and effectiveness of all nodes present in the topography cannot be appropriately estimated and questions like "How reliable is the topography nodes present for distributing workload fairly?" remain unanswered.

There is need for ubicomp reliability studies to well define the equitable distribution of overall energy requirements among all nodes with appropriate mathematical bounds. This definition may then be used for further studies about Fairness. It is desirable in the field of ubicomp to define appropriate metrics, among which some will be relevant to this equitable distribution, and well define its rationale and purposes.

The key contributions of this paper is firstly, the development of two metrics BFEA and ECFP which follow from previous experiments [14]. The two metrics are defined and the rationale of metric ECFP is sufficiently elicited. Secondly, the model of trend is put forward for the metric ECFP with results for varying node densities from 7 until 56 in a topography of $300 \mathrm{x}$ $300 \mathrm{~m}^{2}$. The model proposed combines linear and exponential model. The rest of this paper is organised as follows: section 2- Metrics BFEA and ECFP, section 3- ECFP Trend Assessment over Varying Node Numbers, 4- Conclusion and References. 
Proc. of Sixth International Conference On Advances in Computing, Electronics and Electrical Technology - CEET 2016 Copyright (C) Institute of Research Engineers and Doctors. All rights reserved.

ISBN no. 978-1-63248-109-2 doi: 10.15224/ 978-1-63248-109-2-04

\section{Metrics BFEA and ECFP.}

Strictly assuming that all nodes in the MANET are expected to contribute equally, a new metric is introduced here: the "Basic Fairness Energy Amount" (BFEA).

BFEA $=\underline{\text { Overall energy spent for a CBR transmission }}$ Number of nodes in the topography.

Following the above definition, another metric ECFP is developed using results obtained in previous experiments [14].

ECFP = energy spent by a node for a CBR transmission BFEA

Another way of understanding the ECFP is by what factor is the energy expenditure of a node deviating from that value obtained in the scenario whereby the overall energy expenditure was equally distributed among all nodes in the topography. It can also serve as a measure of reliance on topography nodes to share work of CBR transmission. This metric if appropriately gauged or even predicted, may also serve purposes elaborated in previous paper [21].

\section{ECFP - Trend Assessment over Varying Node Numbers.}

3.0 Major Observations.

For many plots, the leftmost point has been found to be very outlying and hence the leftmost coordinate at $\mathrm{x}$ value 0.0 is not considered.

A peak value after the $5^{\text {th }}$ point is observed. Previous to this peak value, the plot is convincingly linear of form:

$$
F(x)=d * x+f
$$

As from the peak value onwards, the exponential tendency is found with equation of form:

$$
G(x)=a * \exp (b *(x-c))
$$

\subsection{Tabular Summary of Results.}

A tabular summary for results of equations of curves $(\mathrm{F}(\mathrm{x})$ and $\mathrm{G}(\mathrm{x})$ ) is shown below. Column headings are: $\mathrm{A} \rightarrow$ node number, $\mathrm{B} \rightarrow$ Value of parameter a, $\mathrm{C} \rightarrow$ Value of parameter $\mathrm{b}, \mathrm{D} \rightarrow$ Value of parameter $\mathrm{c}, \mathrm{E} \rightarrow$ reduced chi-square value of plot $\mathrm{G}(\mathrm{x}), \mathrm{F} \rightarrow$ Value of parameter $\mathrm{d}, \mathrm{G} \rightarrow$ Value of parameter $\mathrm{f}, \mathrm{H} \rightarrow$ reduced chi-square value of plot $\mathrm{F}(\mathrm{x}), \mathrm{I} \rightarrow$ Corresponding figure number.

\begin{tabular}{|c|c|c|c|c|}
\hline 12 & 2.74038 & -1.21282 & 1.56055 & 0.0441422 \\
\hline 13 & 2.73725 & -1.27098 & 1.54798 & 0.0435918 \\
\hline 14 & 2.73593 & -1.33076 & 1.54272 & 0.0356326 \\
\hline 15 & 2.73128 & -1.49966 & 1.52453 & 0.0117591 \\
\hline 16 & 2.73194 & -1.42091 & 1.52717 & 0.028328 \\
\hline 17 & 2.70514 & -1.45901 & 1.51938 & 0.0153685 \\
\hline 18 & 2.70306 & -1.5066 & 1.51138 & 0.0214786 \\
\hline 19 & 2.70094 & -1.55088 & 1.50313 & 0.0100176 \\
\hline 20 & 2.69923 & -1.58763 & 1.49647 & 0.00891923 \\
\hline 21 & 2.69845 & -1.62136 & 1.49322 & 0.0136481 \\
\hline 22 & 2.69493 & -1.67887 & 1.4793 & 0.0138326 \\
\hline 23 & 2.69408 & -1.68179 & 1.47629 & 0.0110339 \\
\hline 24 & 2.69166 & -1.72099 & 1.4667 & 0.00946568 \\
\hline 25 & 2.69114 & -1.73969 & 1.4645 & 0.00955261 \\
\hline 26 & 2.69121 & -1.76129 & 1.46457 & 0.0111097 \\
\hline 27 & 2.68901 & -1.79335 & 1.45584 & 0.00604357 \\
\hline 28 & 2.68759 & -1.80258 & 1.45046 & 0.00980326 \\
\hline 29 & 2.6939 & -1.6306 & 1.47671 & 0.0345217 \\
\hline 30 & 2.68648 & -1.8204 & 1.44616 & 0.00924871 \\
\hline 31 & 2.68526 & -1.89367 & 1.44017 & 0.0053598 \\
\hline 32 & 2.68392 & -1.8831 & 1.43546 & 0.00815349 \\
\hline 33 & 2.68372 & -1.89383 & 1.43458 & 0.00926095 \\
\hline 34 & 2.68384 & -1.89472 & 1.43517 & 0.0081911 \\
\hline 35 & 2.683 & -1.92048 & 1.43166 & 0.00786014 \\
\hline 36 & 2.68215 & -1.93336 & 1.42845 & 0.00717578 \\
\hline 37 & 2.6888 & -1.73084 & 1.45745 & 0.0359029 \\
\hline 38 & 2.68814 & -1.74014 & 1.45492 & 0.0346124 \\
\hline 39 & 2.68629 & -1.76421 & 1.44777 & 0.030318 \\
\hline 40 & 2.68655 & -1.76131 & 1.44886 & 0.0273212 \\
\hline 41 & 2.67861 & -1.98703 & 1.4144 & 0.00758903 \\
\hline 42 & 2.68597 & -1.7851 & 1.44632 & 0.0284301 \\
\hline 43 & 2.68631 & -1.78042 & 1.44762 & 0.0233208 \\
\hline 44 & 2.67975 & -1.96871 & 1.41882 & 0.00505503 \\
\hline 45 & 2.68502 & -1.8085 & 1.44252 & 0.0214516 \\
\hline 46 & 2.68469 & -1.82437 & 1.441 & 0.0205677 \\
\hline 47 & 2.68422 & -1.83415 & 1.43925 & 0.0189808 \\
\hline 48 & 2.68346 & -1.84086 & 1.43637 & 0.0207305 \\
\hline 49 & 2.68228 & -1.8622 & 1.43187 & 0.0218281 \\
\hline 50 & 2.68097 & -1.86778 & 1.42719 & 0.0221503 \\
\hline 51 & 2.68052 & -1.88306 & 1.4255 & 0.0222656 \\
\hline 52 & 2.67953 & -1.89814 & 1.42183 & 0.0229702 \\
\hline 53 & 2.67881 & -1.90936 & 1.41884 & 0.0239569 \\
\hline 54 & 2.67813 & -1.92373 & 1.41601 & 0.0183675 \\
\hline 55 & 2.67792 & -1.92094 & 1.41526 & 0.0198861 \\
\hline 56 & 2.67781 & -1.92525 & 1.41489 & 0.0211068 \\
\hline
\end{tabular}

\begin{tabular}{|c|c|c|c|c}
\hline $\mathbf{A}$ & $\mathbf{B}$ & $\mathbf{C}$ & $\mathbf{D}$ & $\mathbf{E}$ \\
\hline 7 & 2.71857 & -1.30898 & 1.47591 & 0.0499499 \\
\hline 8 & 2.74961 & -1.1825 & 1.59523 & 0.0343597 \\
\hline 9 & 2.75253 & -1.35826 & 1.60721 & 0.0162001 \\
110 & 2.74147 & -1.2311 & 1.56432 & 0.0393975 \\
\hline 11 & 2.74071 & -1.30215 & 1.56118 & 0.0212923 \\
\hline
\end{tabular}

Table 1(a): summary of results for OFR equations of curves node

\begin{tabular}{|c|c|c|c|c|}
\hline A & $\mathbf{F}$ & $\mathbf{G}$ & H & I \\
\hline 7 & 7.4852 & 0.0213966 & 0.0774396 & 1 \\
\hline 8 & 6.44062 & -0.34255 & 0.0480863 & 2 \\
\hline 9 & 5.99875 & 0.212095 & 0.181385 & 3 \\
\hline 10 & 7.41353 & 0.525959 & 0.171797 & 4 \\
\hline 11 & 8.76791 & 0.0798865 & 0.121207 & 5 \\
\hline 12 & 9.34161 & 0.0961224 & 0.101858 & 6 \\
\hline 13 & 10.4562 & -0.115705 & 0.159502 & 7 \\
\hline 14 & 11.6522 & -0.470805 & 0.156011 & 8 \\
\hline 15 & 10.24 & 0.150817 & 0.4701 & 9 \\
\hline 16 & 12.4829 & -0.575501 & 0.196619 & 10 \\
\hline 17 & 11.4667 & 0.315508 & 0.34154 & 11 \\
\hline 18 & 11.8933 & 0.195458 & 0.468112 & 12 \\
\hline 19 & 12.6162 & 0.0161713 & 0.461486 & 13 \\
\hline 20 & 13.4582 & -0.233766 & 0.579002 & 14 \\
\hline 21 & 13.2428 & -0.124927 & 0.562364 & 15 \\
\hline 22 & 13.7575 & -0.225939 & 0.57217 & 16 \\
\hline 23 & 14.2586 & -0.328156 & 0.801312 & 17 \\
\hline 24 & 14.5647 & -0.37696 & 0.693879 & 18 \\
\hline 25 & 14.9674 & -0.511128 & 0.710069 & 19 \\
\hline 26 & 14.6362 & -0.347342 & 0.717674 & 20 \\
\hline 27 & 15.6031 & -0.61978 & 0.914949 & 21 \\
\hline 28 & 15.4999 & -0.54117 & 0.940157 & 22 \\
\hline 29 & 16.742 & -0.883635 & 1.24367 & 23 \\
\hline 30 & 16.0284 & -0.669476 & 0.964785 & 24 \\
\hline 31 & 16.8538 & -0.962903 & 1.08542 & 25 \\
\hline 32 & 16.777 & -0.909314 & 1.0312 & 26 \\
\hline 33 & 16.7886 & -0.90757 & 0.857766 & 27 \\
\hline
\end{tabular}
numbers 7-56 
Proc. of Sixth International Conference On Advances in Computing, Electronics and Electrical Technology - CEET 2016 Copyright (C) Institute of Research Engineers and Doctors. All rights reserved.

ISBN no. 978-1-63248-109-2 doi: 10.15224/ 978-1-63248-109-2-04

\begin{tabular}{|c|c|c|c|c|}
\hline 34 & 16.9673 & -0.965285 & 0.975781 & 28 \\
\hline 35 & 17.2914 & -1.06689 & 0.975787 & 29 \\
\hline 36 & 17.3786 & -1.05994 & 0.99823 & 30 \\
\hline 37 & 18.5899 & -1.33289 & 1.31209 & 31 \\
\hline 38 & 18.882 & -1.41376 & 1.28608 & 32 \\
\hline 39 & 19.0998 & -1.43088 & 1.35059 & 33 \\
\hline 40 & 19.27 & -1.47332 & 1.36753 & 34 \\
\hline 41 & 18.1399 & -1.19065 & 1.2463 & 35 \\
\hline 42 & 19.5181 & -1.57772 & 1.43016 & 36 \\
\hline 43 & 19.9165 & -1.67733 & 1.41167 & 37 \\
\hline 44 & 18.5862 & -1.32472 & 1.32784 & 38 \\
\hline 45 & 20.2619 & -1.78101 & 1.63735 & 39 \\
\hline 46 & 20.4025 & -1.84664 & 1.58382 & 40 \\
\hline 47 & 20.8218 & -1.9729 & 1.7571 & 41 \\
\hline 48 & 21.0863 & -2.03711 & 1.71729 & 42 \\
\hline 49 & 21.2021 & -2.05499 & 1.76117 & 43 \\
\hline 50 & 21.2057 & -1.97598 & 1.54788 & 44 \\
\hline 51 & 21.4352 & -2.05571 & 1.64411 & 45 \\
\hline 52 & 21.504 & -2.06076 & 1.67938 & 46 \\
\hline 53 & 21.616 & -2.07924 & 1.69956 & 47 \\
\hline 54 & 21.957 & -2.16429 & 1.79753 & 48 \\
\hline 55 & 22.1204 & -2.20029 & 1.77763 & 49 \\
\hline 56 & 22.0429 & -2.18074 & 1.77067 & 50 \\
\hline
\end{tabular}

Table 1(b): summary of results for OFR equations of curves node numbers 7-56

\subsection{Graphical Plots for Results Obtained.}

This analysis is performed in gnuplot in Linux.

\section{Node Number 7}

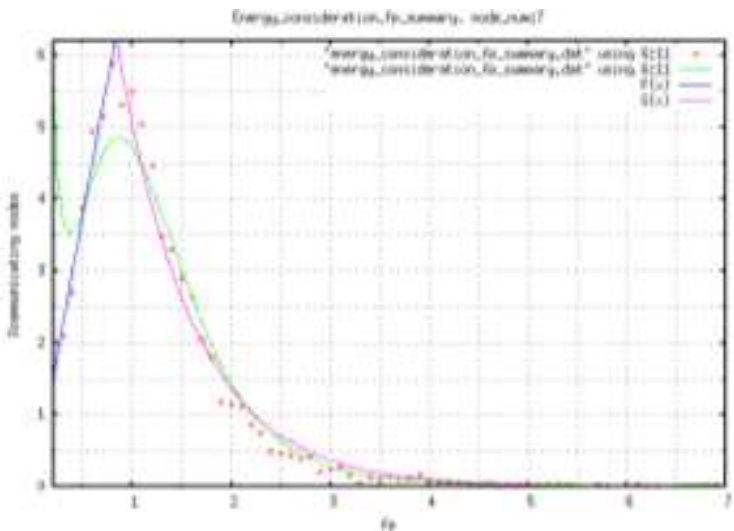

Figure 1: \% communicating nodes for ECFP node_number 7

2. Node Number 8

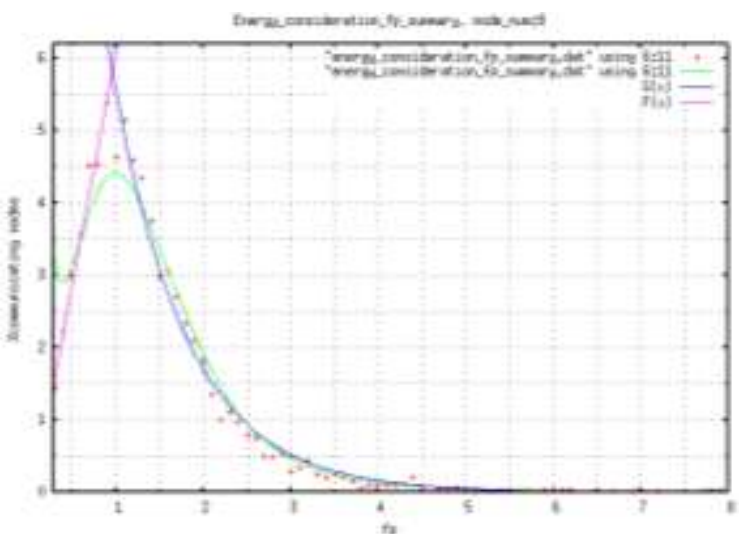

Figure 2: \% communicating nodes for ECFP node_number 8 3. Node Number 9

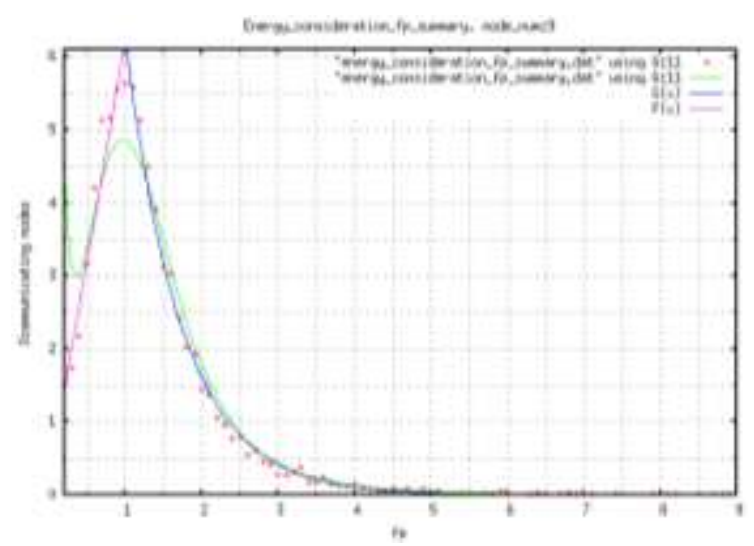

Figure 3: \% communicating nodes for ECFP node_number 9

4. Node Number 10

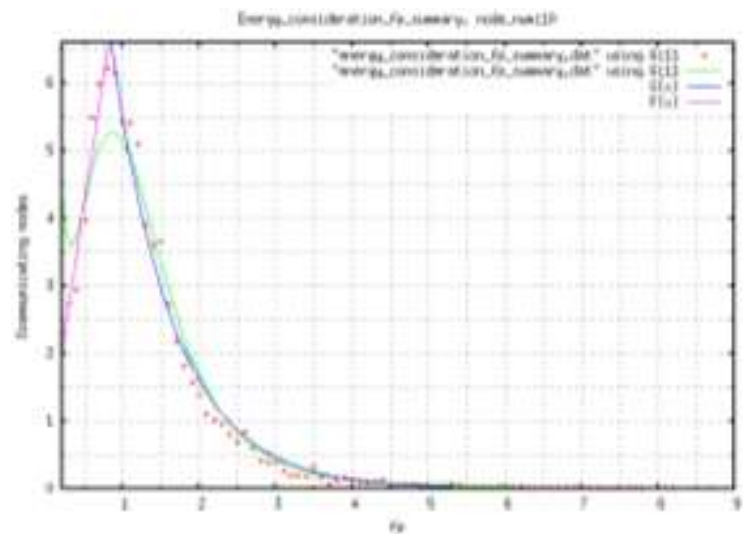

Figure 4: \% communicating nodes for ECFP node_number 10 5. Node Number 11

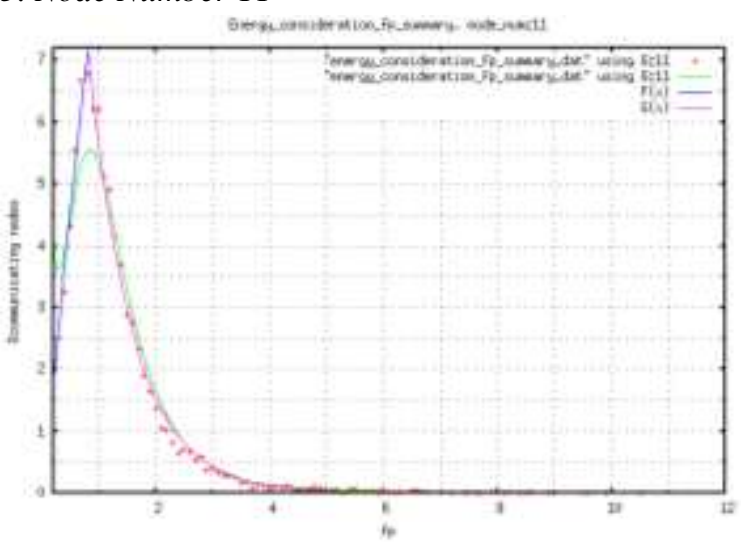

Figure 5: \% communicating nodes for ECFP node_number 11 6. Node Number 12

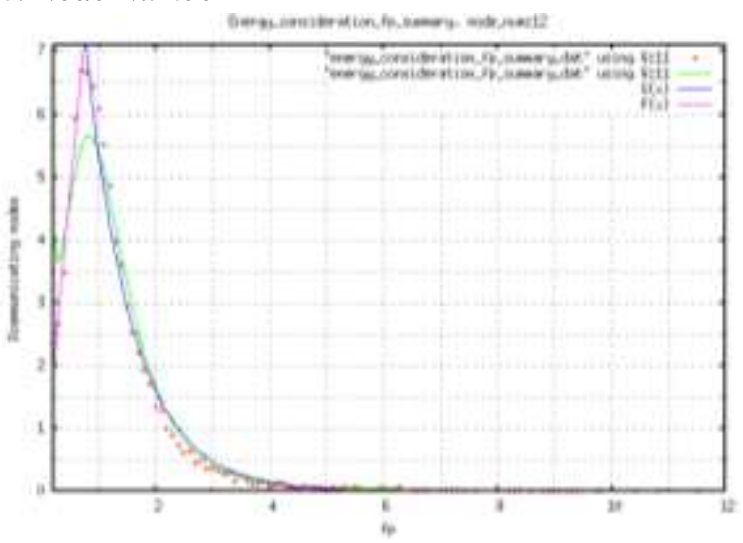

Figure 6: \% communicating nodes for ECFP node_number 12 7. Node Number 13 
Proc. of Sixth International Conference On Advances in Computing, Electronics and Electrical Technology - CEET 2016 Copyright (C) Institute of Research Engineers and Doctors. All rights reserved.

ISBN no. 978-1-63248-109-2 doi: 10.15224/ 978-1-63248-109-2-04

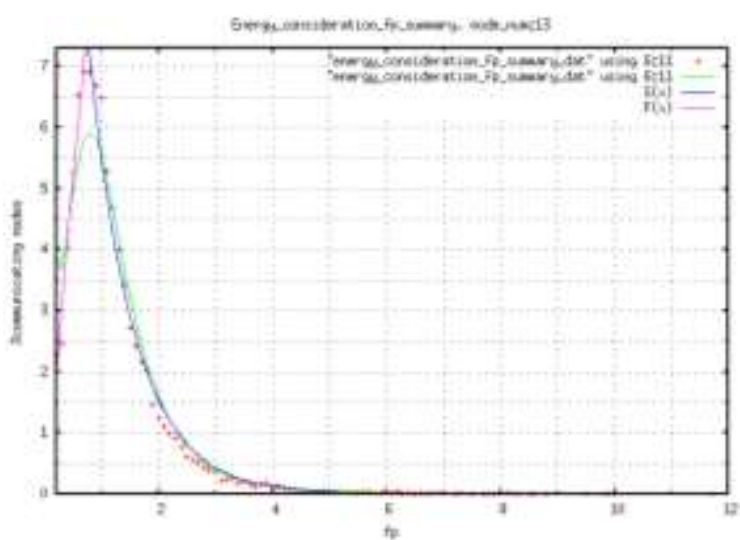

Figure 7: \% communicating nodes for ECFP node_number 13 8. Node Number 14

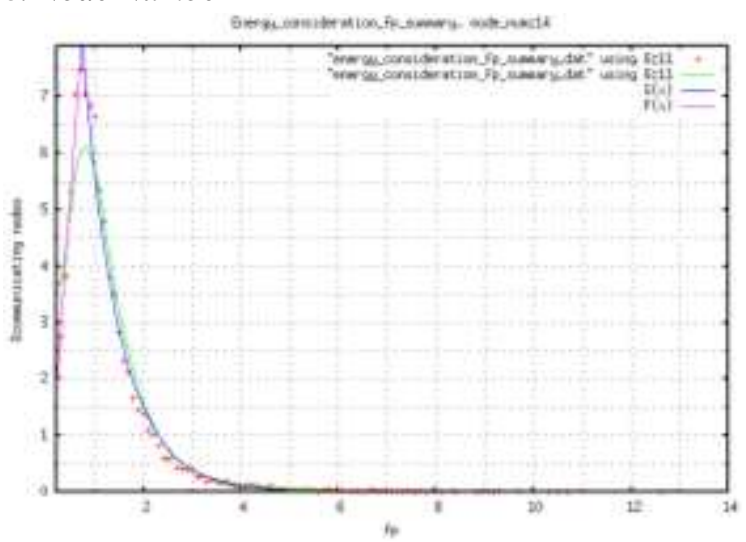

Figure 8: \% communicating nodes for ECFP node_number 14 9. Node Number 15

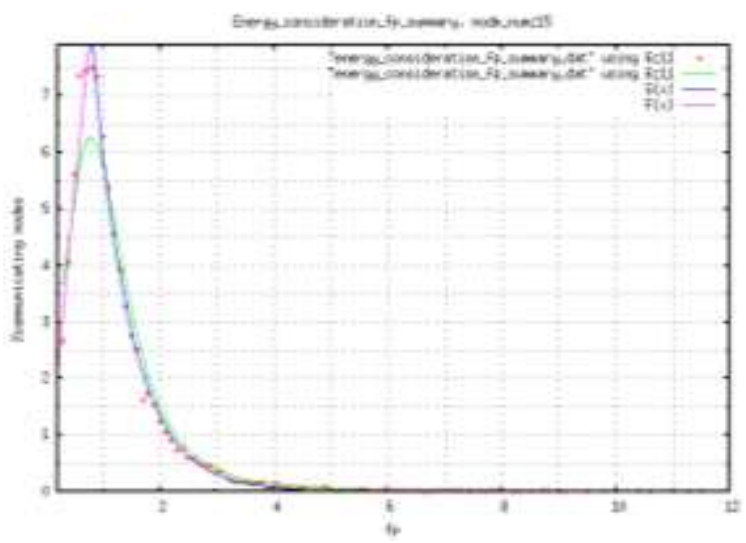

Figure 9: \% communicating nodes for ECFP node_number 15 10. Node Number 16

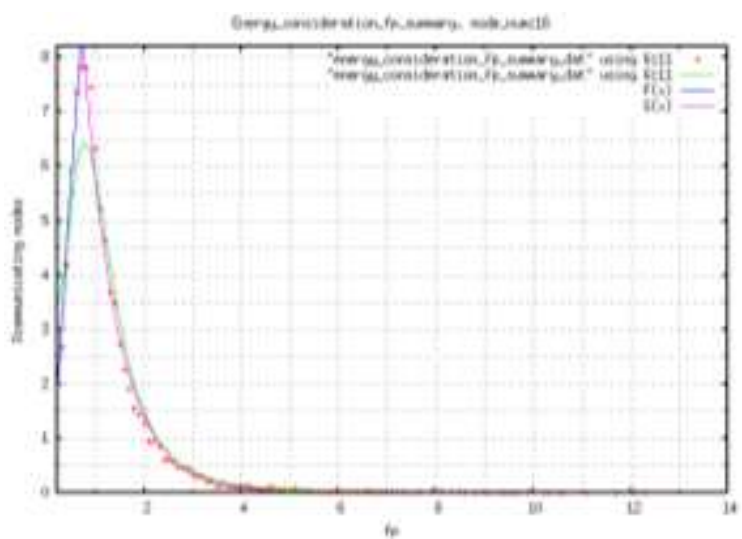

Figure 10: \% communicating nodes for ECFP node_number 16 11. Node Number 17

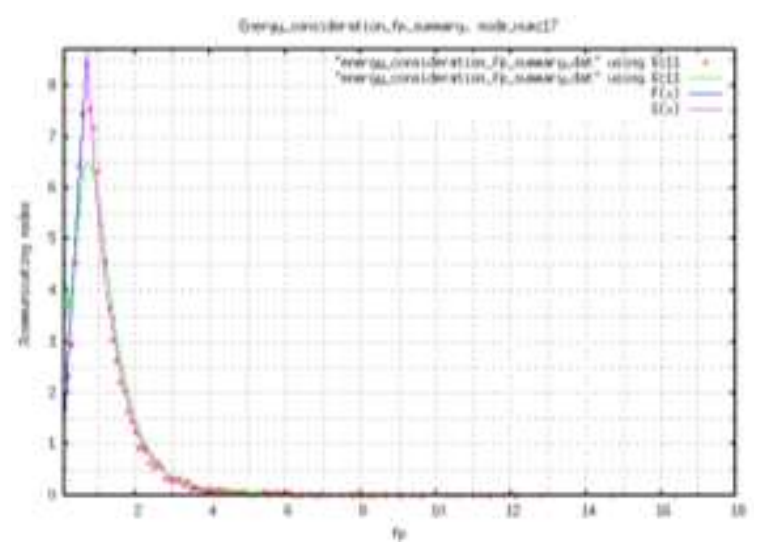

Figure 11: \% communicating nodes for ECFP node_number 17 12. Node Number 18

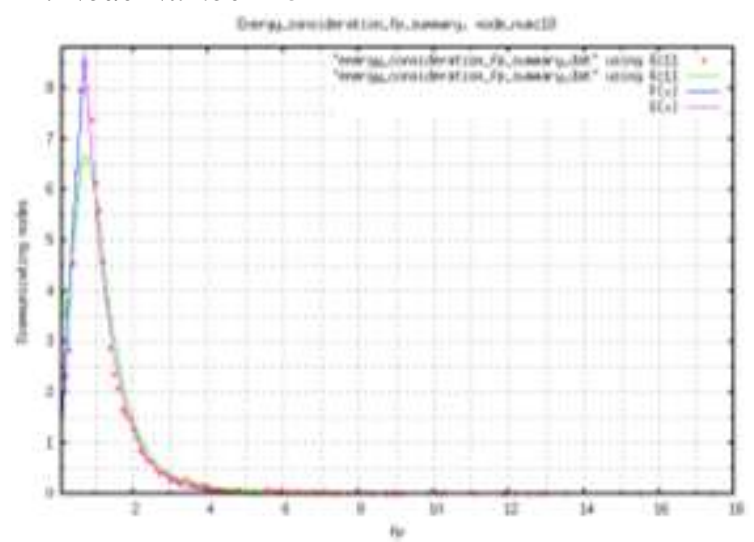

Figure 12: \% communicating nodes for ECFP node_number 18 13. Node Number 19

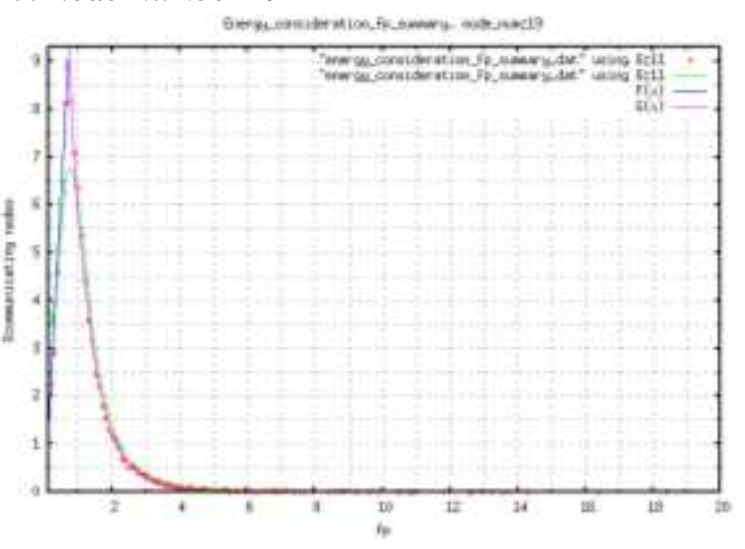

Figure 13: \% communicating nodes for ECFP node_number 19 14. Node Number 20

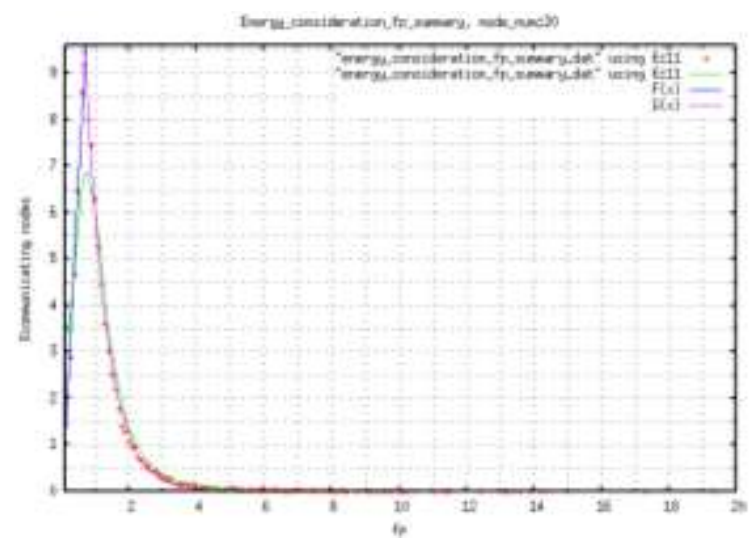

Figure 14: \% communicating nodes for ECFP node_number 20 15. Node Number 21 
Proc. of Sixth International Conference On Advances in Computing, Electronics and Electrical Technology - CEET 2016 Copyright (C) Institute of Research Engineers and Doctors. All rights reserved.

ISBN no. 978-1-63248-109-2 doi: 10.15224/ 978-1-63248-109-2-04

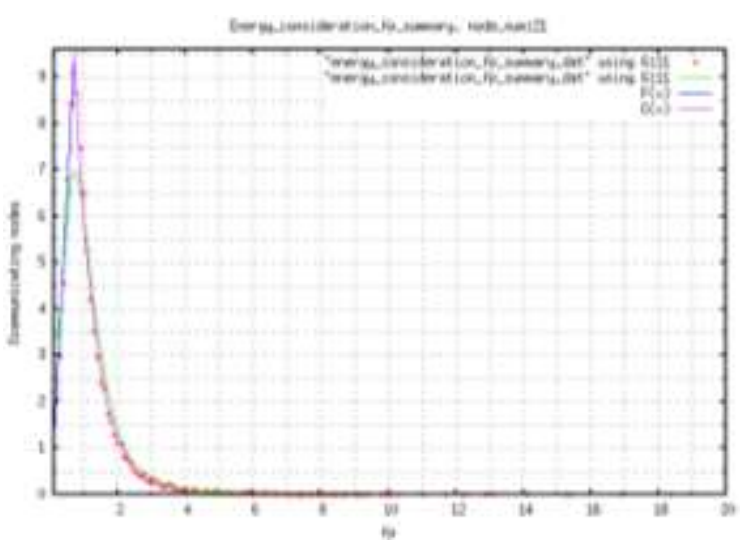

Figure 15: \% communicating nodes for ECFP node_number 21 16. Node Number 22

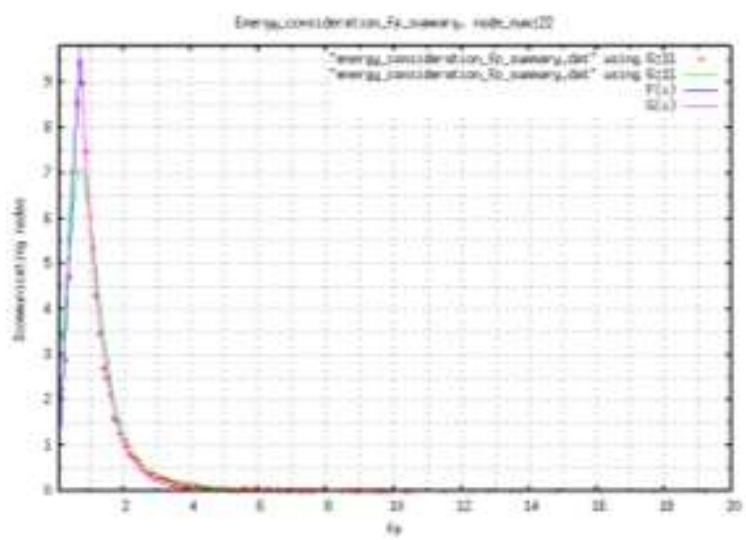

Figure 16: \% communicating nodes for ECFP node_number 22 17. Node Number 23

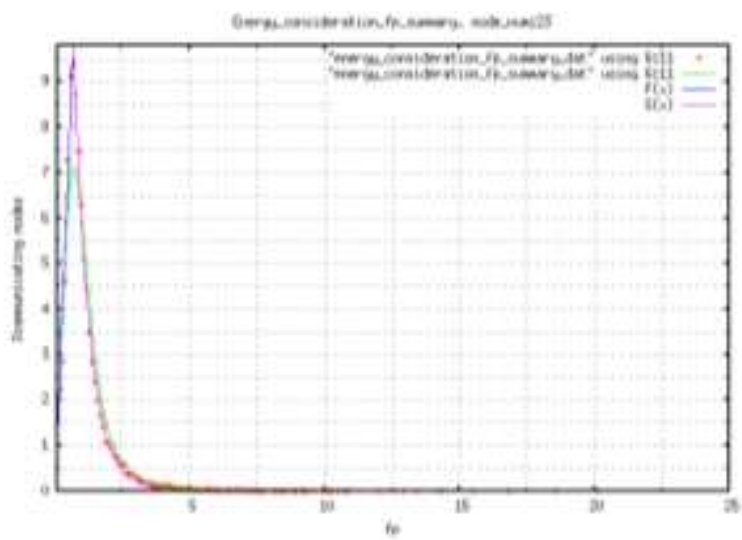

Figure 17: \% communicating nodes for ECFP node_number 23 18. Node Number 24

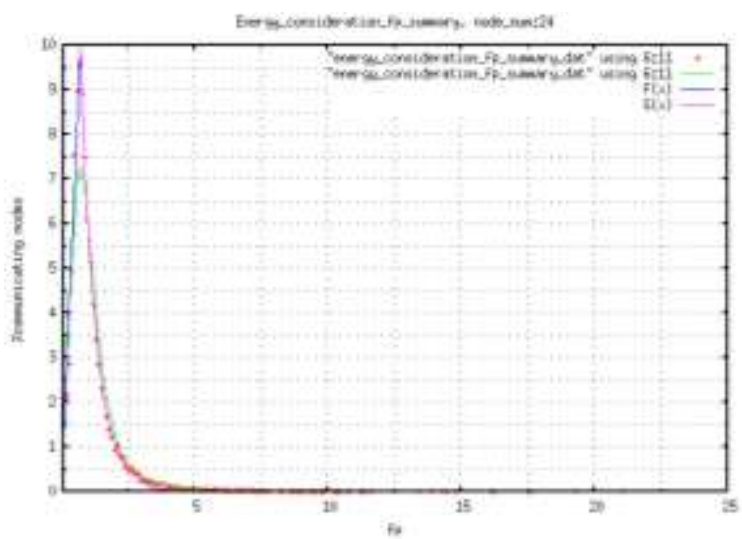

Figure 18: \% communicating nodes for ECFP node_number 24 19. Node Number 25

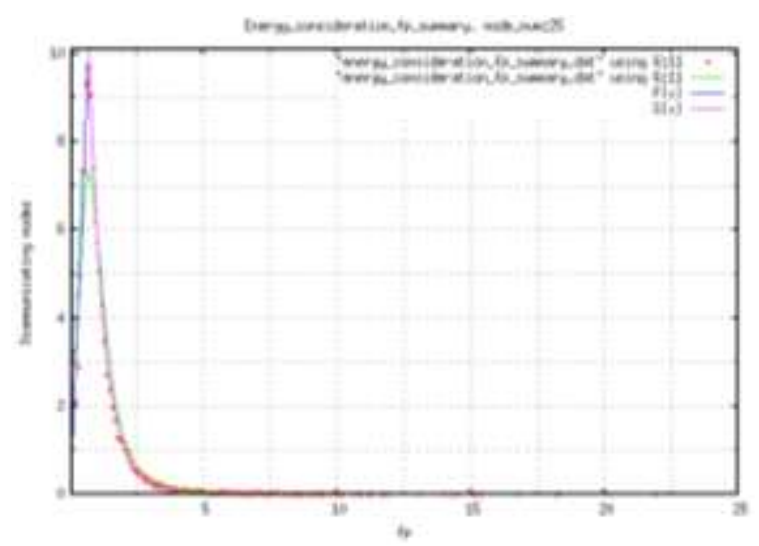

Figure 19: \% communicating nodes for ECFP node_number 25 20. Node Number 26

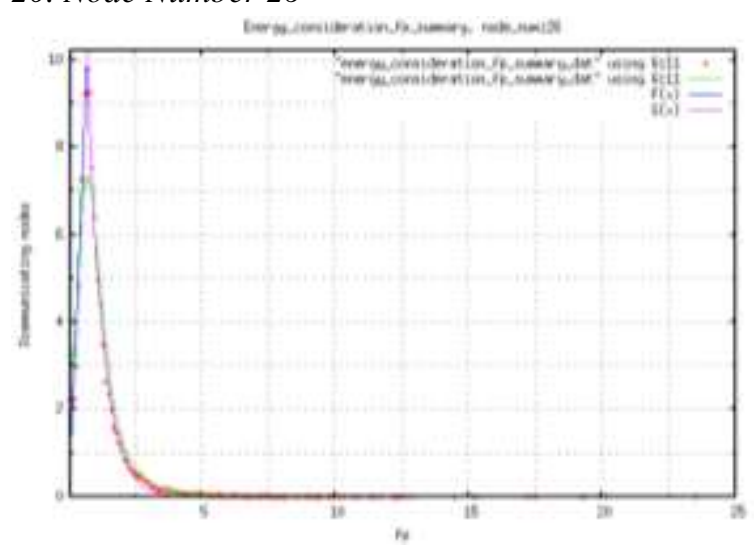

Figure 20: \% communicating nodes for ECFP node_number 26 21. Node Number 27

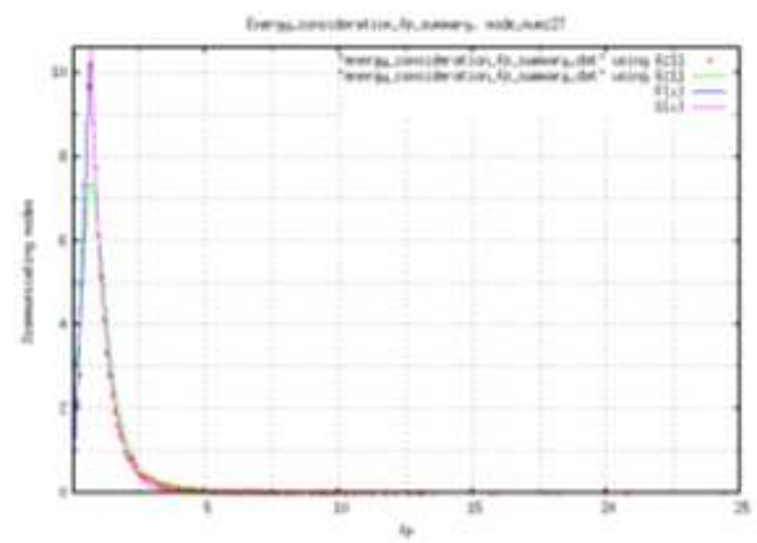

Figure 21: \% communicating nodes for ECFP node_number 27 22. Node Number 28

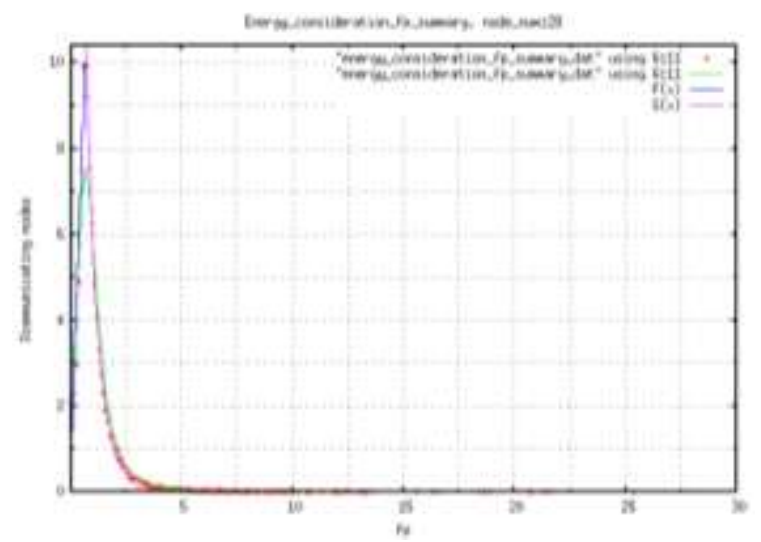

Figure 22: \% communicating nodes for ECFP node_number 28 23. Node Number 29 
Proc. of Sixth International Conference On Advances in Computing, Electronics and Electrical Technology - CEET 2016 Copyright (C) Institute of Research Engineers and Doctors. All rights reserved.

ISBN no. 978-1-63248-109-2 doi: 10.15224/ 978-1-63248-109-2-04

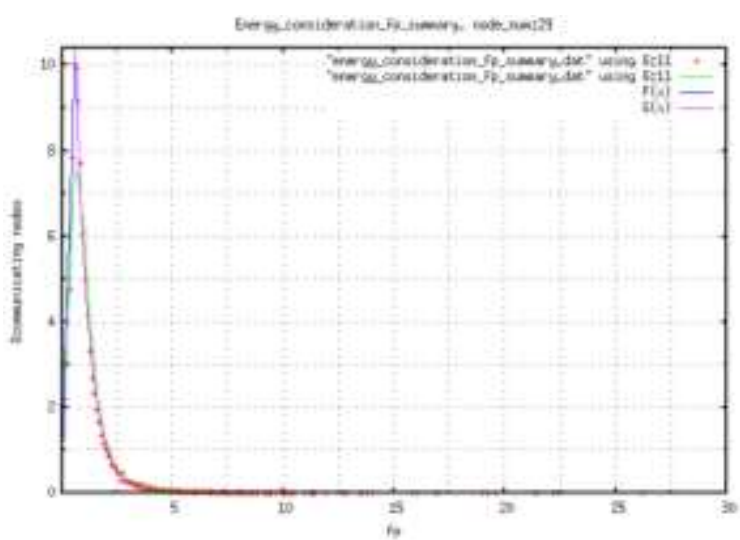

Figure 23: \% communicating nodes for ECFP node_number 29 24. Node Number 30

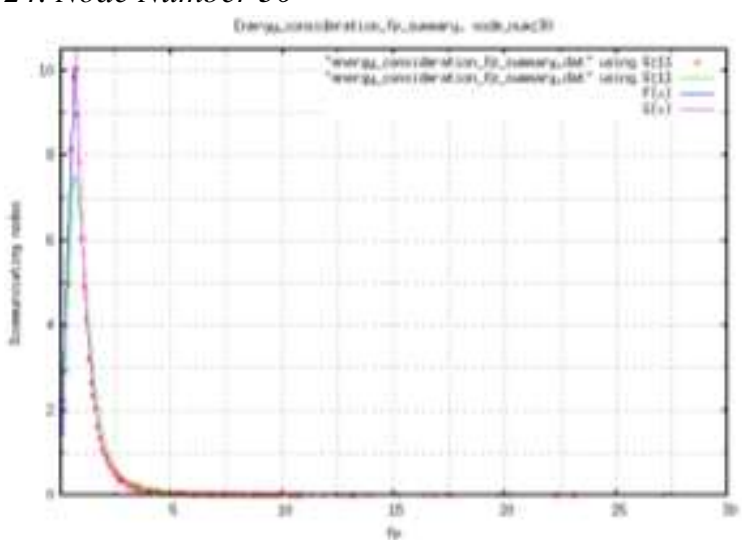

Figure 24: \% communicating nodes for ECFP node_number 30 25. Node Number 31

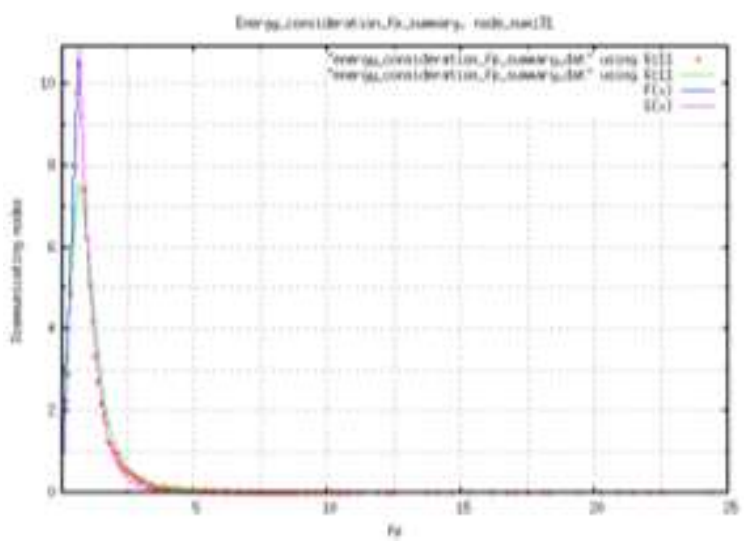

Figure 25: \% communicating nodes for ECFP node_number 31 26. Node Number 32

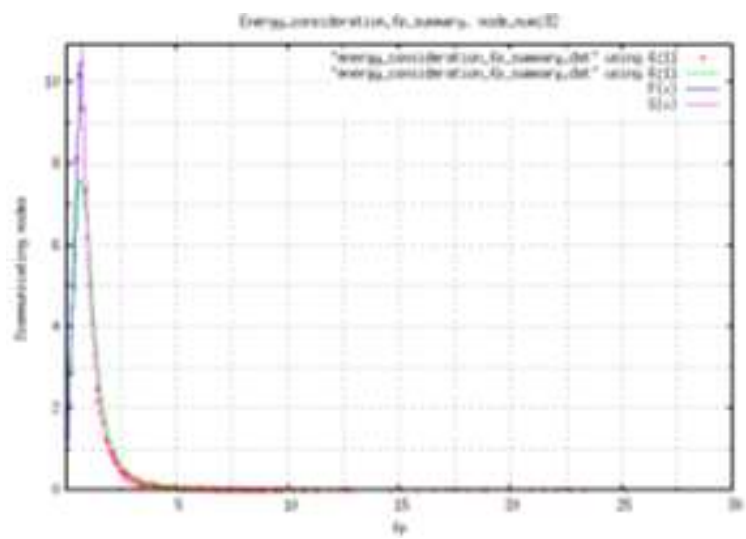

Figure 26: \% communicating nodes for ECFP node_number 32 27. Node Number 33

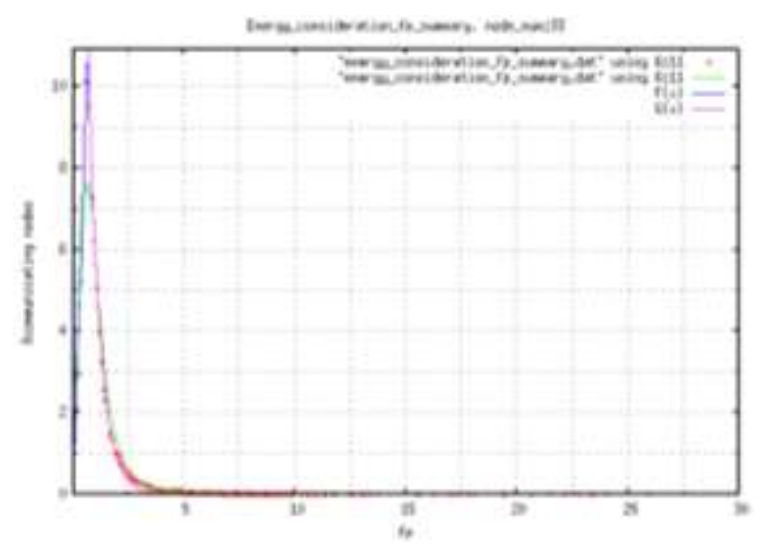

Figure 27: \% communicating nodes for ECFP node_number 33 28. Node Number 34

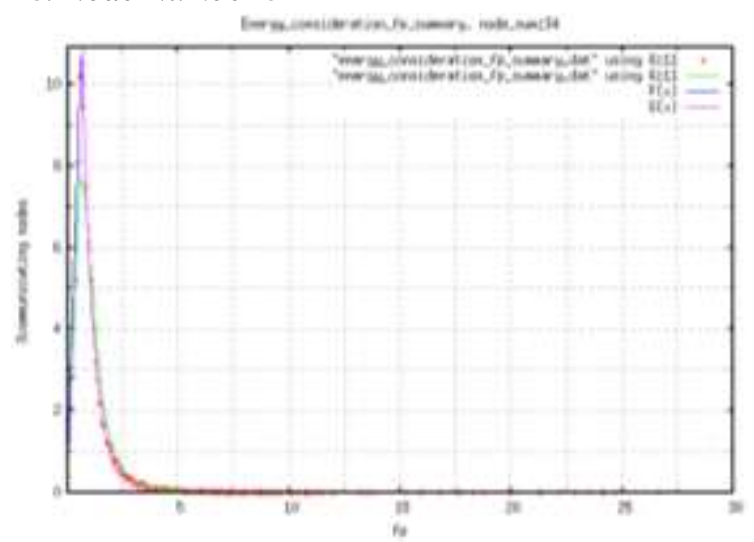

Figure 28: \% communicating nodes for ECFP node_number 34 29. Node Number 35

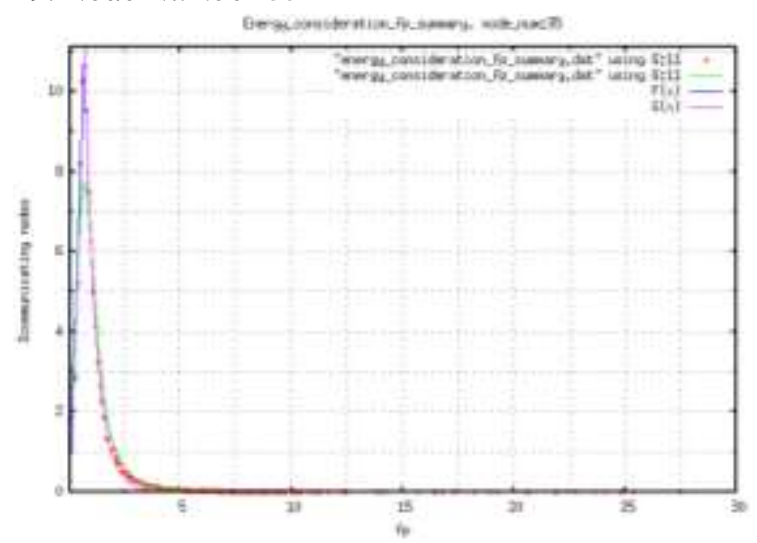

Figure 29: \% communicating nodes for ECFP node_number 35 30. Node Number 36

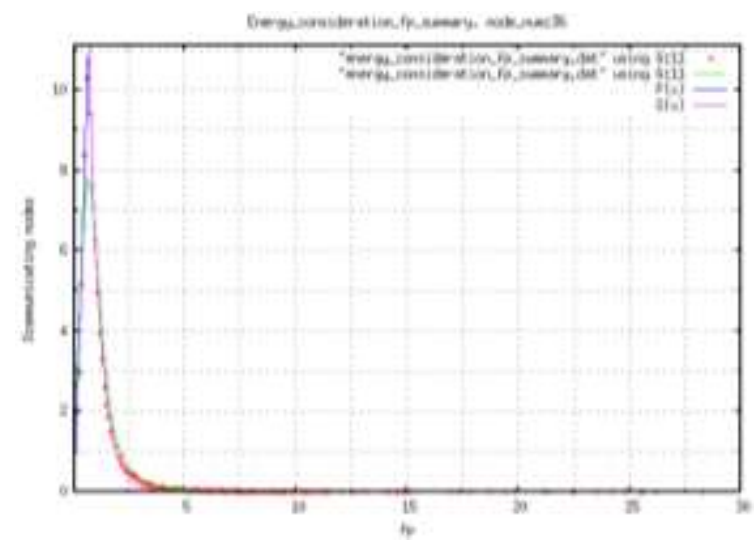

Figure 30: \% communicating nodes for ECFP node_number 36 31. Node Number 37 
Proc. of Sixth International Conference On Advances in Computing, Electronics and Electrical Technology - CEET 2016 Copyright (C) Institute of Research Engineers and Doctors. All rights reserved.

ISBN no. 978-1-63248-109-2 doi: 10.15224/ 978-1-63248-109-2-04

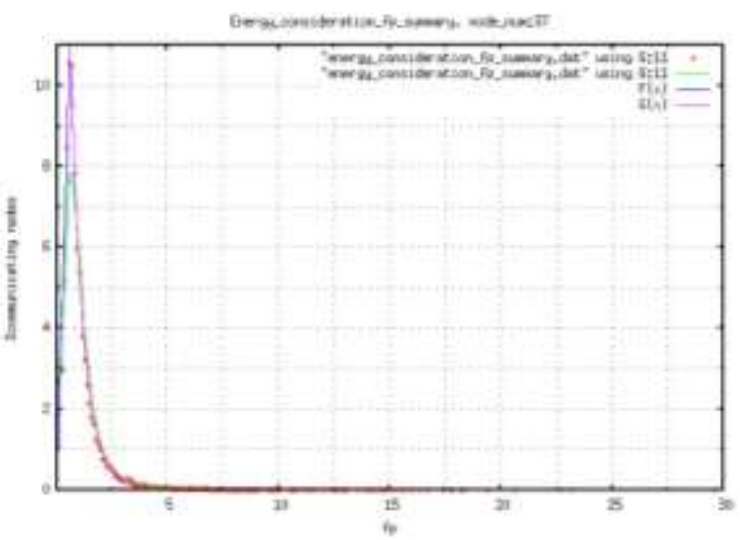

Figure 31: \% communicating nodes for ECFP node_number 37 32. Node Number 38

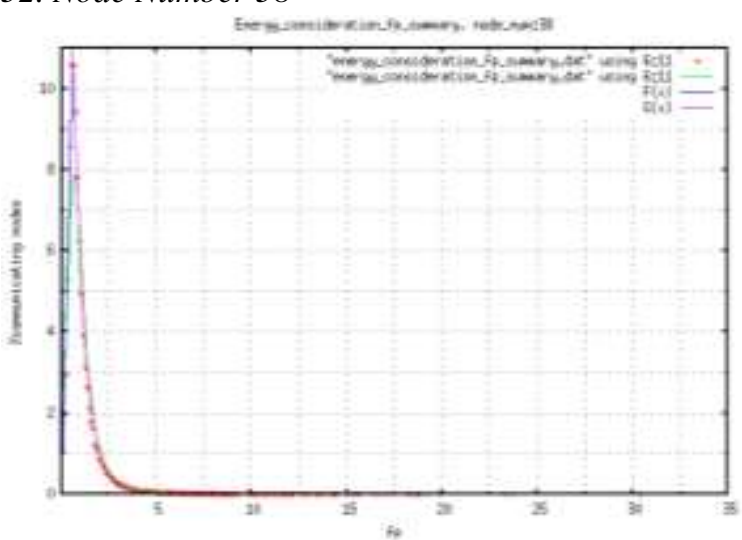

Figure 32: \% communicating nodes for ECFP node_number 38 33. Node Number 39

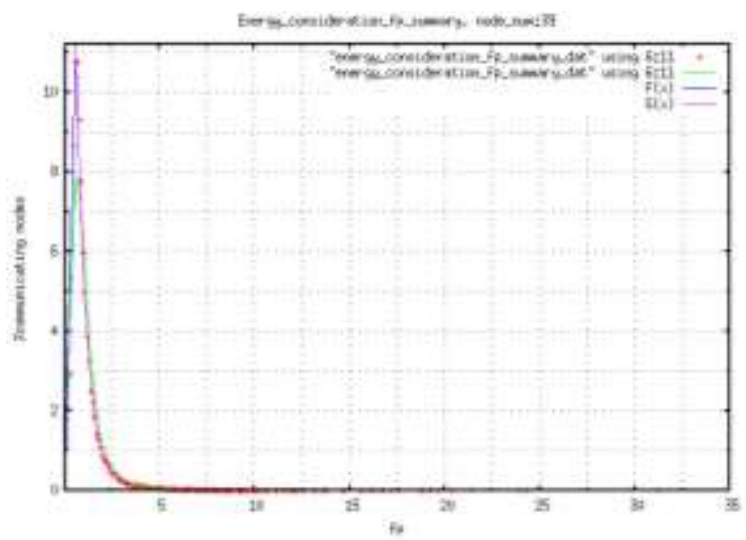

Figure 33: \% communicating nodes for ECFP node_number 39 34. Node Number 40

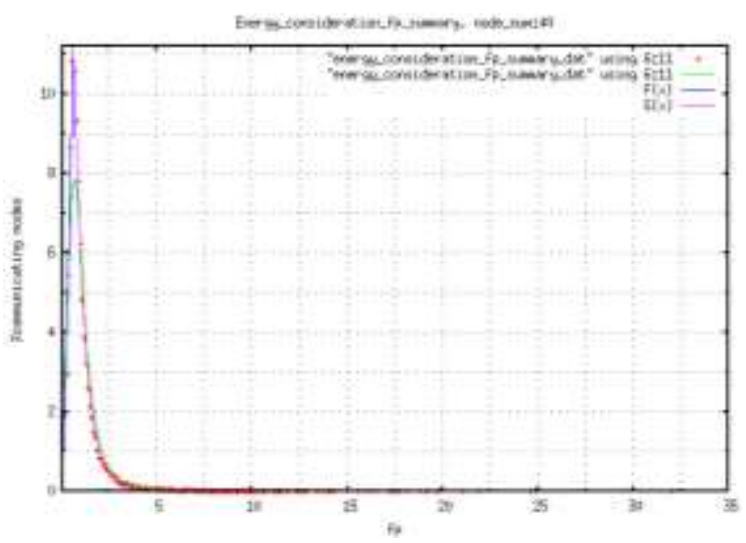

Figure 34: \% communicating nodes for ECFP node_number 40 35. Node Number 41

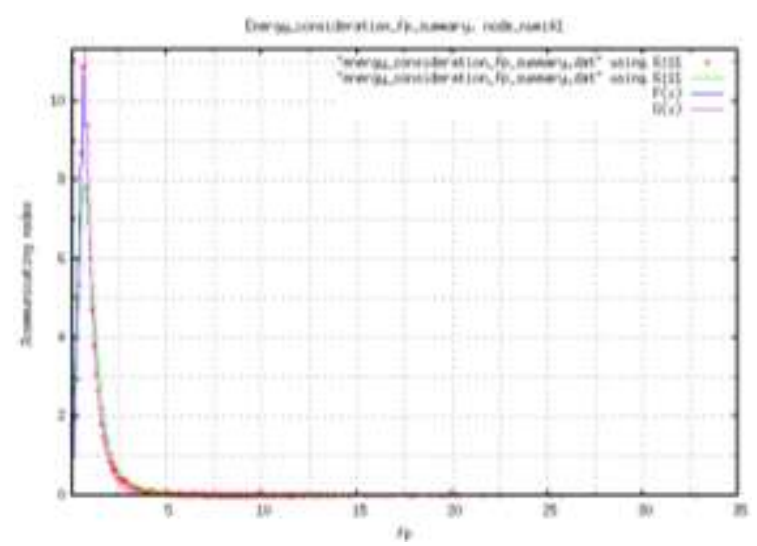

Figure 35: \% communicating nodes for ECFP node_number 41 36. Node Number 42

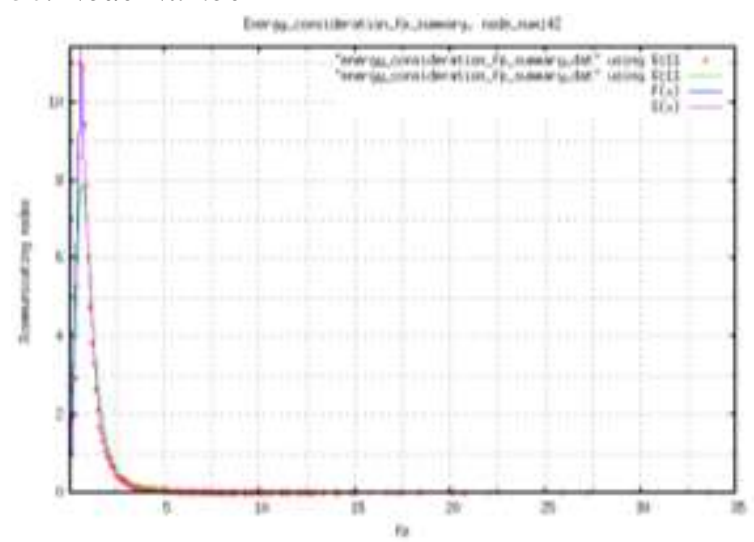

Figure 36: \% communicating nodes for ECFP node_number 42 37. Node Number 43

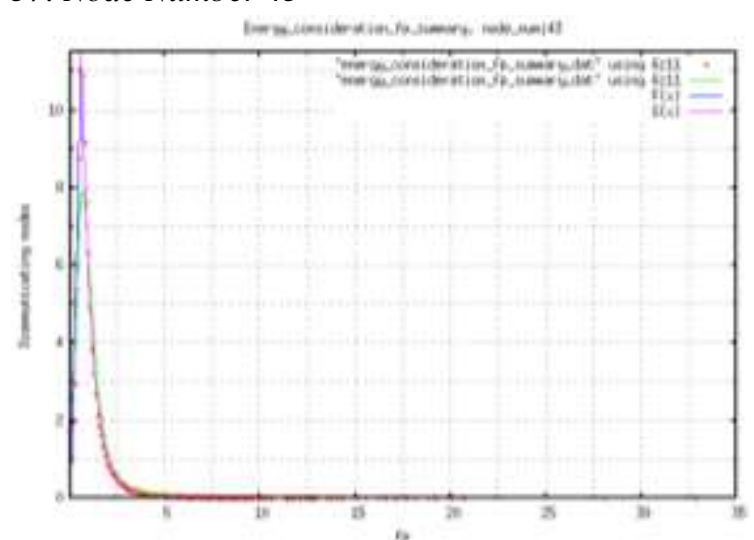

Figure 37: \% communicating nodes for ECFP node_number 43 38. Node Number 44

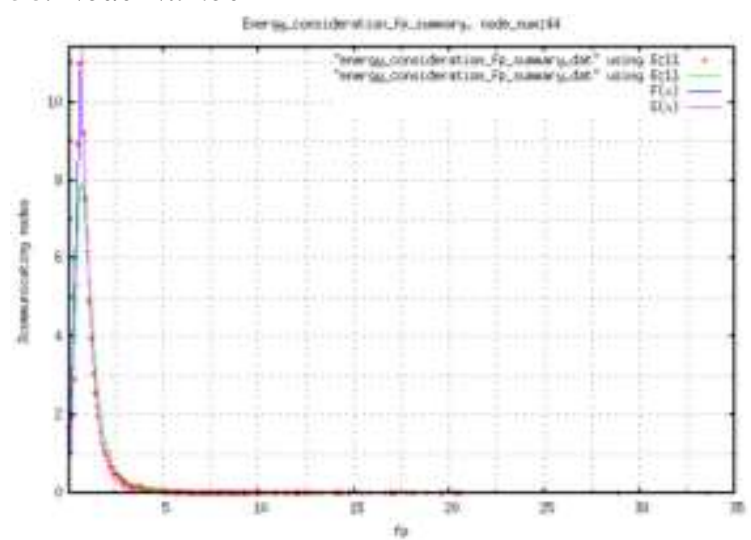

Figure 38: \% communicating nodes for ECFP node_number 44 39. Node Number 45 
Proc. of Sixth International Conference On Advances in Computing, Electronics and Electrical Technology - CEET 2016 Copyright (C) Institute of Research Engineers and Doctors. All rights reserved.

ISBN no. 978-1-63248-109-2 doi: 10.15224/ 978-1-63248-109-2-04

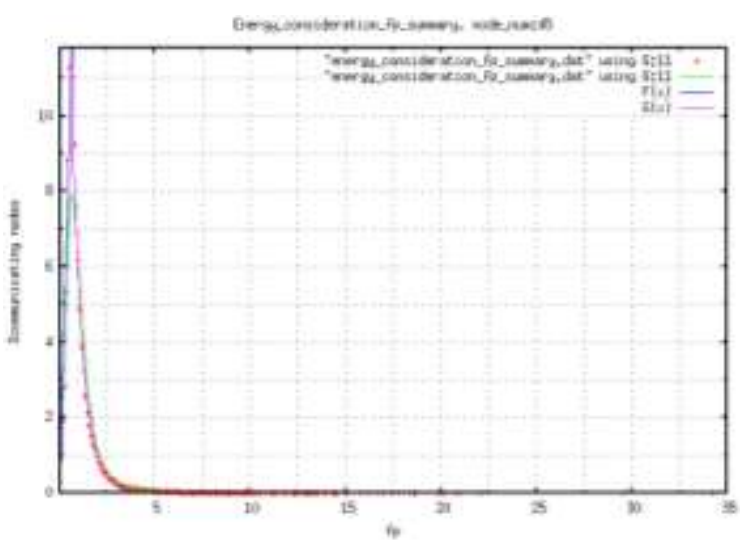

Figure 39: \% communicating nodes for ECFP node_number 45 40. Node Number 46

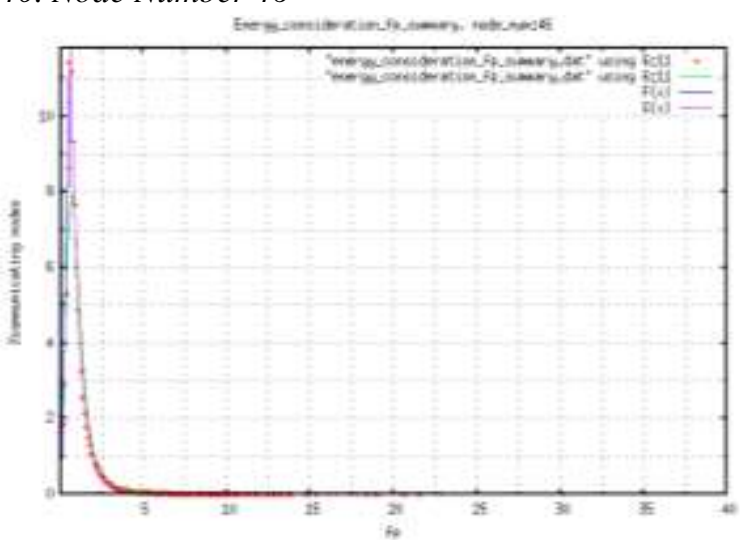

Figure 40: \% communicating nodes for ECFP node_number 46 41. Node Number 47

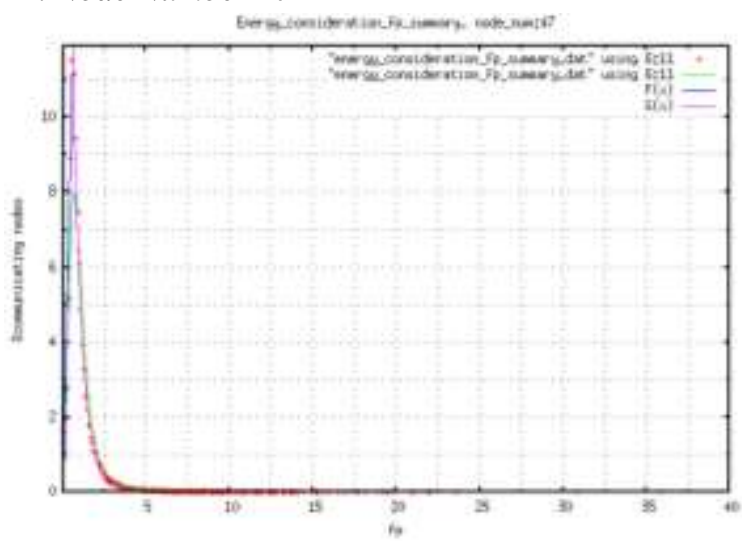

Figure 41: \% communicating nodes for ECFP node_number 47 42. Node Number 48

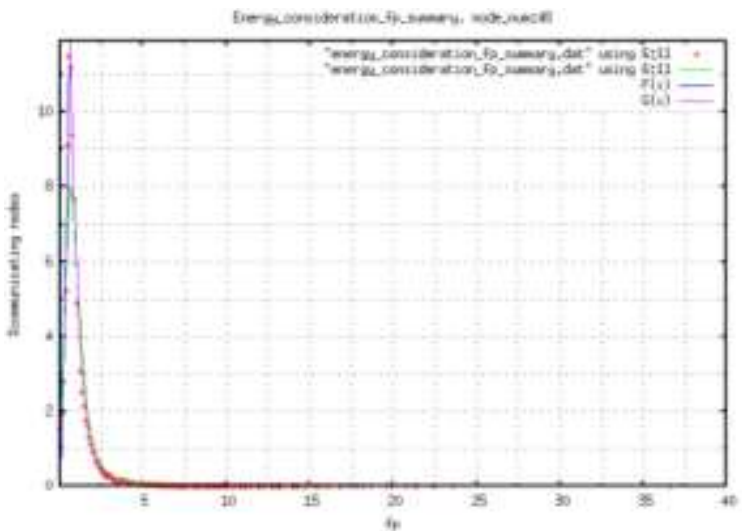

Figure 42: \% communicating nodes for ECFP node_number 48 43. Node Number 49

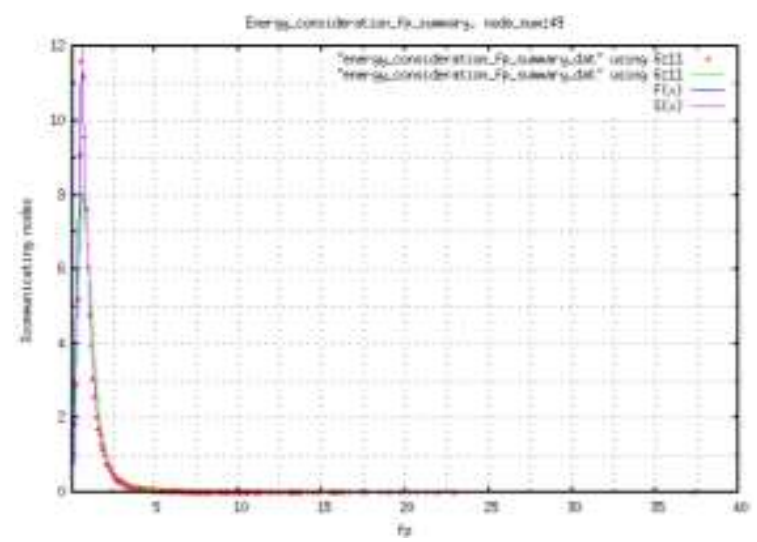

Figure 43: \% communicating nodes for ECFP node_number 49 44. Node Number 50

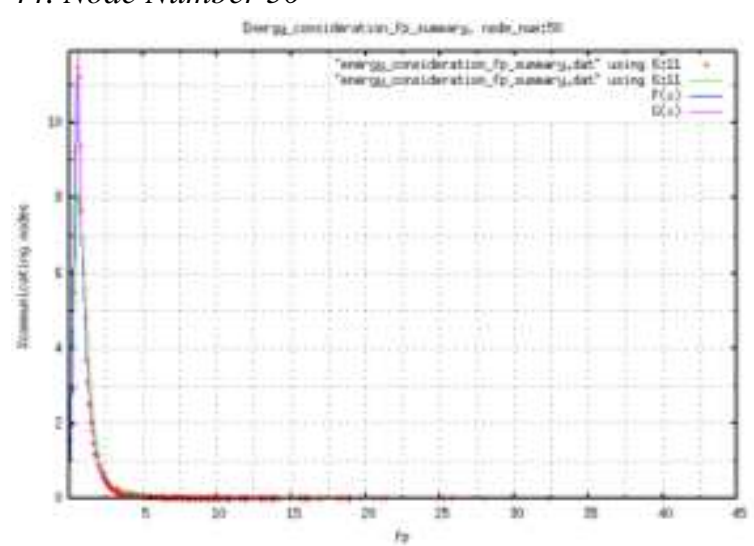

Figure 44: \% communicating nodes for ECFP node_number 50 45. Node Number 51

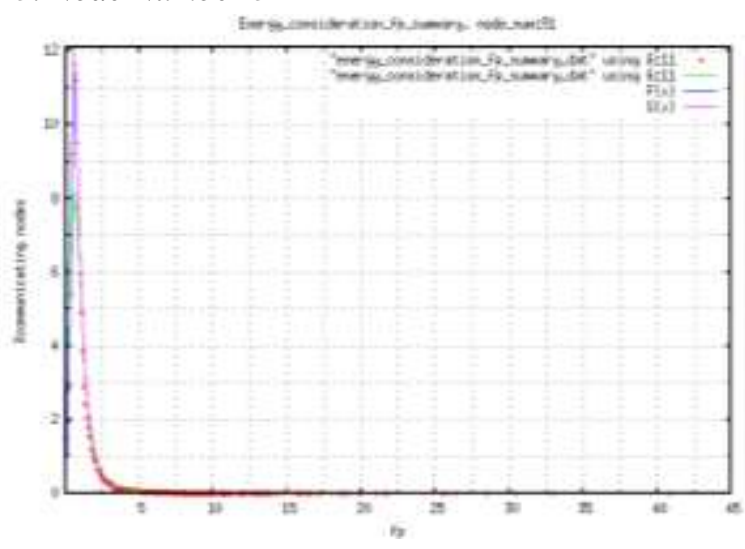

Figure 45: \% communicating nodes for ECFP node_number 51 46. Node Number 52

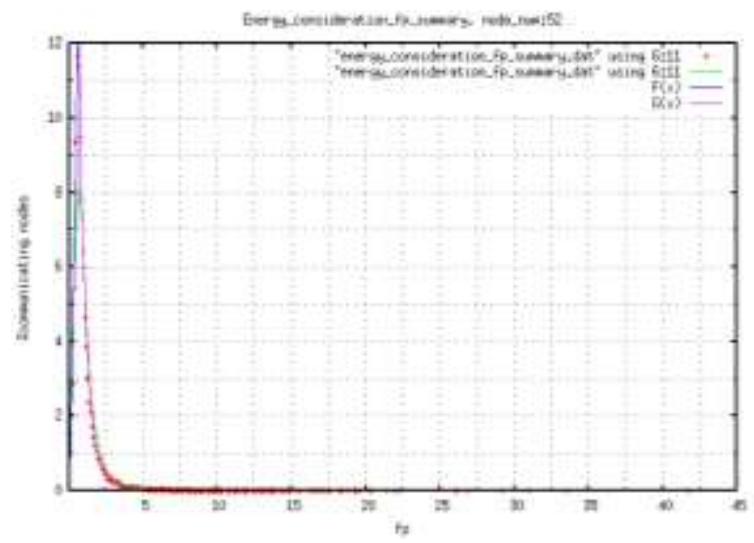

Figure 46: \% communicating nodes for ECFP node_number 52 47. Node Number 53 
Proc. of Sixth International Conference On Advances in Computing, Electronics and Electrical Technology - CEET 2016 Copyright (C) Institute of Research Engineers and Doctors. All rights reserved.

ISBN no. 978-1-63248-109-2 doi: 10.15224/ 978-1-63248-109-2-04

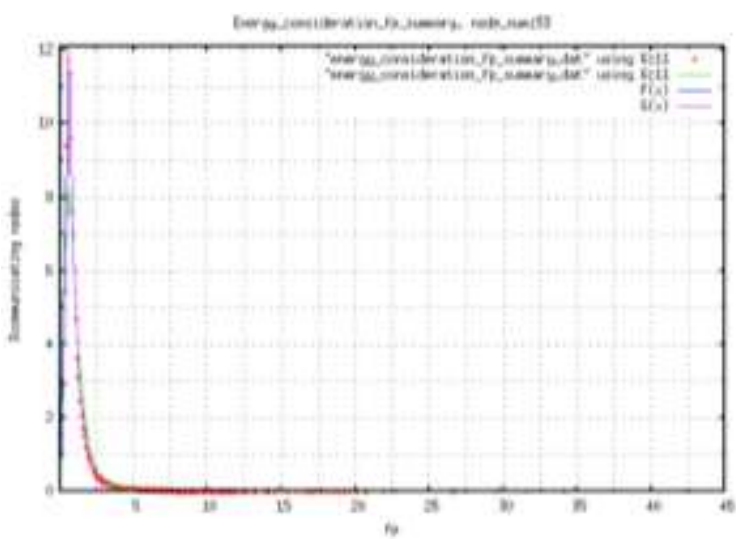

Figure 47: \% communicating nodes for ECFP node_number 53 48. Node Number 54

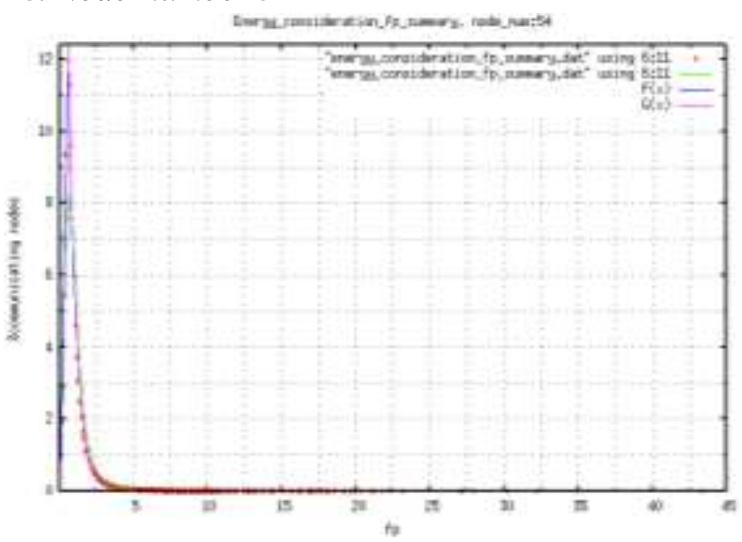

Figure 48: \% communicating nodes for ECFP node_number 54 49. Node Number 55

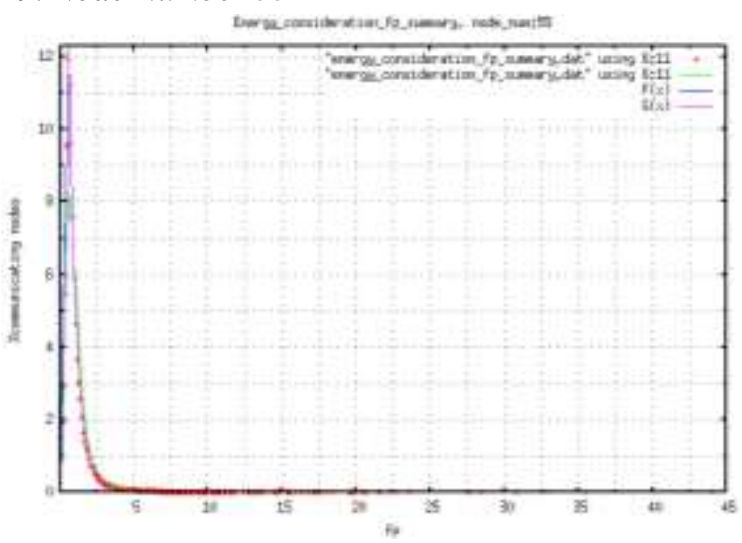

Figure 49: \% communicating nodes for ECFP node_number 55 50. Node Number 56

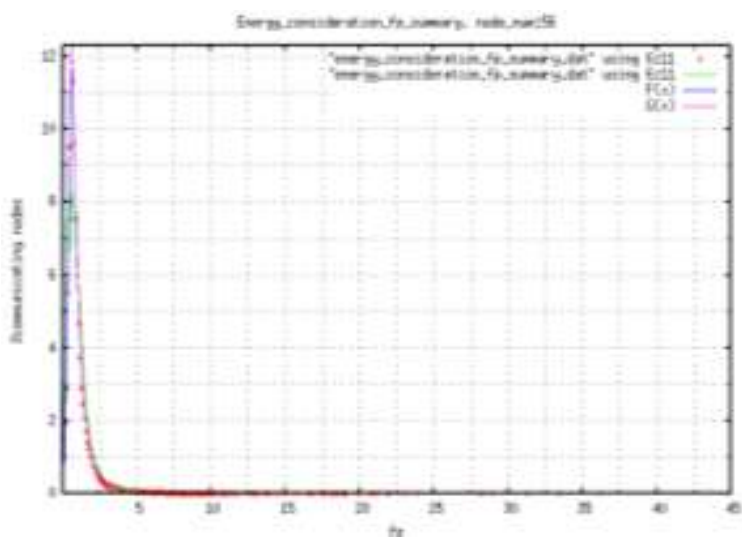

Figure 50: \% communicating nodes for ECFP node_number 56

\section{Conclusion.}

This piece of research was aimed at studying trends of fairness reached in ubicomp as concerns energy load distribution. This research differs from previous work [18-21] in the sense that here, equitable distribution of energy among all topographic nodes present is assumed. For this purpose, a metric BFEA has been developed to define this equitable distribution of energy. Following definition of BFEA, another metric, ECFP, has been developed and its rationale and purposes also put forward. This study remains empirical-based and was implemented over same experiment as explained previously [15]. The model put forward combines the exponential and linear models. Again, previously stated assumptions [21] hold, e.g. availability of lightweight algorithms for location-aware transmission in mobile environments, lightweight MAUC OS supports for efficient binding/unbinding of MANET nodes and appropriate multi-threading/parallel communication in modules of MANET nodes.

The further work identified may include: trend analyses of parameters of equations for the model, formulating methods of predictability for metric ECFP and its trend and reporting observations of certain critical values identified. Development of further metrics for studying Fairness in ubicomp remain desirable. Other research avenues remain development of further metrics and methods for assessing Fairness in energy expenditure of participating nodes in MANET transmission, together with the trend analyses.

\section{References}

[1] M. Kaleem GALAMALI, Assoc. Prof Nawaz MOHAMUDALLY, Towards Dependable Pervasive Systems-A Position and Vision Paper, CEET 2014

[2] M. Kaleem GALAMALI, Assoc. Prof Nawaz MOHAMUDALLY, Model of Energy Savings achievable with Location-aware Node-to-Node Transmission in UbiComp , CEET 2014

[3] M. Kaleem GALAMALI, Assoc. Prof Nawaz MOHAMUDALLY, Model of Energy Savings achievable with Location-aware Node-to-Node Transmission in UbiComp Using Location Refresh Intervals, CEET 2014

[4] M. Kaleem GALAMALI, Assoc. Prof Nawaz MOHAMUDALLY, Model of Energy Savings achievable with Location-aware Transmission in UbiComp Using Relays, CEET 2014

[5] M. Kaleem GALAMALI, Assoc. Prof Nawaz MOHAMUDALLY, Mathematical modeling of need of exact number of relays to ensure seamless mobility in mobile computing, CEET 2014

[6] M. Kaleem GALAMALI, Assoc. Prof Nawaz MOHAMUDALLY, Modelling of need for multiple relays for ensuring seamless mobility, CEET 2014

[7] M. Kaleem GALAMALI, Assoc. Prof Nawaz MOHAMUDALLY, Investigation of prominence of placements of relays in a ubicomp topography, 
Proc. of Sixth International Conference On Advances in Computing, Electronics and Electrical Technology - CEET 2016 Copyright (C) Institute of Research Engineers and Doctors. All rights reserved.

ISBN no. 978-1-63248-109-2 doi: 10.15224/ 978-1-63248-109-2-04

[8] M. Kaleem GALAMALI, Assoc. Prof Nawaz MOHAMUDALLY, Model of energy savings achievable with location-aware transmission in ubicomp using optimised number of relays.

[9] M. Kaleem GALAMALI, Assoc. Prof Nawaz MOHAMUDALLY, Investigation of Prominence of Placements of Optimised Number of Relays in a Ubicomp Topography using Location-Aware Transmission, CEET 2015

[10] M. Kaleem GALAMALI, Assoc. Prof Nawaz MOHAMUDALLY, Extending Node Battery Availability in Ubicomp with Location-Aware Transmission, CEET 2015.

[11] M. Kaleem GALAMALI, Assoc. Prof Nawaz MOHAMUDALLY, Extending Node Battery Availability in Ubicomp with Location-Aware Transmission using Location Refresh Intervals, CEET 2015.

[12] M. Kaleem GALAMALI, Assoc. Prof Nawaz MOHAMUDALLY, Extending Node Battery Availability in Ubicomp with Location-Aware Transmission using Uniformly Placed Relays, CEET 2015.

[13] M. Kaleem GALAMALI, Assoc. Prof Nawaz MOHAMUDALLY, Extending Node Battery Availability in Ubicomp with Location-Aware Transmission Using Optimally Placed Relays, CEET 2015.

[14] M. Kaleem GALAMALI, Assoc. Prof Nawaz MOHAMUDALLY, Model of Sender Node Energy Savings Achievable with Location-Aware MANET Transmission in Ubicomp, ACCN 2016

[15] M. Kaleem GALAMALI, Assoc. Prof Nawaz MOHAMUDALLY, Model of Overall Node Energy Savings Achievable with Location-Aware MANET Transmission in Ubicomp, ACCN 2016

[16] M. Kaleem GALAMALI, Assoc. Prof Nawaz MOHAMUDALLY, Model of Sender Node Extra Energy Savings Achievable in MANET Against Direct Node-toNode Transmission Using Location-Aware Transmission in Ubicomp, ACCN 2016

[17] M. Kaleem GALAMALI, Assoc. Prof Nawaz MOHAMUDALLY, Model of Overall Node Extra Energy Savings Achievable in MANET against Direct Node-toNode Transmission Using Location-Aware Transmission in Ubicomp, ACCN 2016

[18] M. Kaleem GALAMALI, Assoc. Prof Nawaz MOHAMUDALLY, Model of Energy Consumption Ratio Achievable in MANET Using Location-Aware Transmission in Ubicomp, ACCN 2016

[19] M. Kaleem GALAMALI, Assoc. Prof Nawaz MOHAMUDALLY, Model of Minimum Energy Consumption Ratio Achievable in MANET Using LocationAware Transmission in Ubicomp, ACCN 2016

[20] M. Kaleem GALAMALI, Assoc. Prof Nawaz MOHAMUDALLY, Model of Maximum Energy Consumption Ratio Achievable in MANET Using LocationAware Transmission in Ubicomp, ACCN 2016

[21] M. Kaleem GALAMALI, Assoc. Prof Nawaz MOHAMUDALLY, Model of Overall Energy Consumption Fairness Ratio Achievable in MANET Using LocationAware Transmission in Ubicomp, ACCN 2016

[22] Markus Bylund and Zary Segall, Towards seamless mobility with personal servers, 2004

[23] Masugi Inoue, Mikio Hasegawa, Nobuo Ryoki and Hiroyuki Morikawa, Context-Based Seamless Network and Application Control, 2004

[24] Xiang Song, Umakishore Ramachandran, MobiGo: A Middleware for Seamless Mobility, College of Computing Georgia Institute of Technology, Atlanta, GA, USA, August 2007

[25] Budzisz, Ferrús, R., Brunstrom A., Grinnemo, K, Fracchia, R., Galante, G., and Casadevall, F. Towards transport-layer mobility: Evolution of SCTP multihoming, March 2008

[26] Paul Dourish \& Genevieve Bell, Divining a digital future, 2011.

[27] Xiang Song, Seamless Mobility In Ubiquitous Computing Environments, $\mathrm{PhD}$ Thesis, Georgia Institute of Technology, August 2008

[28] Kevin O Mahony, Jian Liang, Kieran Delaney, User-Centric Personalization and Autonomous Reconfiguration Across
Ubiquitous Computing Environments, NIMBUS Centre Cork Institute of Technology, Cork, Ireland, UBICOMM 2012

[29] Pablo Vidales, Seamless mobility in 4G systems, Technical Report, University of Cambridge, Computer Laboratory, Number 656, November 2005

[30] João Pedro Sousa and David Garlan, Aura: An Architectural Framework for User Mobility in Ubiquitous Computing Environments, School of Computer Science, Carnegie Mellon University, USA, August 2002

[31] Dennis Lupiana, Ciaran O'Driscoll, Fredrick Mtenzi, Defining Smart Space in the Context of Ubiquitous Computing, Dublin Institute of Technology, Ireland, Special Issue on ICIT 2009 Conference - Web and Agent Systems, 2009

[32] N.S.V.Shet1, Prof.K.Chandrasekaran2 and Prof. K.C.Shet3, WAP Based Seamless Roaming In Urban Environment with Wise Handoff Technique, International Journal of UbiComp (IJU), Vol.1, No.4, October 2010

[33] Yipeng Yu Dan He Weidong Hua Shijian Li Yu Qi Yueming Wang Gang Pan, FlyingBuddy2: A BraincontrolledAssistant for the Handicapped, Zhejiang University, UbiComp'12, September 5-8, 2012.

[34] Jing Su, James Scott, Pan Hui, Jon Crowcroft, Eyal de Lara Christophe Diot, Ashvin Goel, Meng How Lim, and Eben Upton, Haggle: Seamless Networking for Mobile Applications, 2007

[35] Rui Han, Moustafa M. Ghanem, Li Guo, Yike Guo*, Michelle Osmond, Enabling cost-aware and adaptive elasticity of multi-tier cloud applications, Future Generation Computer Systems, 2012

[36] Byrav Ramamurthy, K. K. Ramakrishnan, Rakesh K. Sinha, Cost and Reliability Considerations in Designing the NextGeneration IP over WDM Backbone Networks, 2012.

[37] Bhavish Aggarwal, Aditya Akella, Ashok Anand, Athula Balachandran, Pushkar Chitnis, Chitra Muthukrishnan, Ram Ramjee and George Varghese, EndRE: An End-System Redundancy Elimination Service for Enterprises, NSDI 2010, San Jose, CA

[38] Ashok Anand, Vyas Sekar and Aditya Akella, SmartRE: An Architecture for Coordinated Network-wide Redundancy Elimination, SIGCOMM 2009, Barcelona, Spain

[39] John Breeden II, "Smart-phone battery life could double without better batteries", Nov 14, 2012

[40] Andy Boxall, "When will your phone battery last as long as your kindle", December 5, 2012

[41] Imielinski, T. and Navas, J.C. (1999). GPS-based geographic addressing, routing, and resource discovery. Comms. ACM Vol. 42, No. 4, pp. 86-92.

[42] Hightower, J. and Borriello, G. (2001). Location Systems for Ubiquitous Computing. IEEE Computer, Vol. 34, No. 8, August, pp. 57-66.

[43] Harter, A., Hopper, A., Steggles, P., Ward, A. and Webster, P. (2002). The Anatomy of a Context-Aware Application. Wireless Networks, Vol. 8, No. 2-3, Mar-May, pp. 187-197.

[44] Hightower, J., Brumitt, B. and Borriello, G. (2002). The Location Stack: A Layered Model for Location in Ubiquitous Computing. Proceedings of the 4th IEEE Workshop on Mobile Computing Systems \& Applications (WMCSA 2002), Callicoon, NY, USA, June, pp. 22-28.

[45] Graumann, D., Lara, W., Hightower, J. and Borriello, G. (2003). Real-world implementation of the Location Stack: The Universal Location Framework. Proceedings of the 5th IEEE Workshop on Mobile Computing Systems \& Applications (WMCSA 2003), Monterey, CA, USA, October, pp. 122-128.

[46] Ko, Y., \& Vaidya, N. H. (2000). Location-aided routing (LAR) in mobile ad hoc networks. Wireless Networks, 6(4), 307-321.

[47] Liao, W.-H., Tseng, Y.-C., \& Sheu, J.-P. (2001). GRID: a fully location-aware routing protocol for mobile ad hoc networks. Telecommunication Systems, 18(1), 37-60.

[48] Kuhn, F., Wattenhofer, R., Zhang, Y., \& Zollinger, A. (2003). Geometric ad-hoc routing: of theory and practice. In Proceedings of the ACM (PODC'03) (pp. 63-72). 
Proc. of Sixth International Conference On Advances in Computing, Electronics and Electrical Technology - CEET 2016

Copyright $(\subseteq)$ Institute of Research Engineers and Doctors. All rights reserved.

ISBN no. 978-1-63248-109-2 doi: 10.15224/ 978-1-63248-109-2-04

[49] Jiang, X., \& Camp, T. (2002). Review of geocasting protocols for a mobile ad hoc network. In Proceedings of the Grace Hopper Celebration (GHC).

[50] Ko, Y. \& Vaidya, N. H. (1999). Geocasting in mobile ad hoc networks: location-based multicast algorithms. In Proceedings of the IEEE (WMCSA '99) (pp. 101).

[51] Mauve, M., Fuler, H., Widmer, J., \& Lang, T. (2003). Position-based multicast routing for mobile ad-hoc networks (Technical Report TR-03-004). Department of Computer Science, University of Mannheim.

[52] Xu, Y., Heidemann, J., \& Estrin, D. (2001). Geographyinformed energy conservation for adhoc routing. In Proceedings of the ACM/IEEE (MOBICOM'01) (pp. 70-84).

[53] Hu, Y.-C., Perrig, A., \& Johnson, D. (2003). Packet leashes: a defense against wormhole attacks in wireless ad hoc networks. In Proceedings of the INFOCOM' 03 (pp. 19761986).

[54] Patwari, N., Hero III, A. O., Perkins, M., Correal, N. S., \& O’Dea, R. J. (2003). Relative location estimation in wireless sensor networks. IEEE Transactions on Signal Processing, 51(8), 2137-2148.

[55] Baldauf, M., Dustdar, S., \& Rosenberg, F. (2007). A Survey on Context Aware Systems. International Journal of Ad Hoc and Ubiquitous Computing, Inderscience Publishers. forthcoming. Pre-print from: http://www.vitalab.tuwien.ac.at/ florian/ papers/ijahuc2007.pdf

[56] Hong, D., Chiu, D.K.W., \& Shen, V.Y. (2005). Requirements elicitation for the design of context-aware applications in a ubiquitous environment. In Proceedings of ICEC'05 (pp. 590-596).

[57] Neeraj Tantubay, Dinesh Ratan Gautam and Mukesh Kumar Dhariwal, A Review of Power Conservation in Wireless Mobile Ad hoc Network (MANET)", International Journal of computer Science Issues, Vol 8, Issue 4, No 1, July 2011.

[58] Wenrui Zhao, Mostafa Ammar and Ellen Zegura, "A Message Ferrying Approach for Data Delivery in Sparse Mobile Ad Hoc Networks", MobiHoc'04, May 24-26, 2004, Roppongi, Japan.

About Author (s):

Associate Professor Nawaz Mohamudally works at University of Technology, Mauritius (UTM) and has undertaken supervision of MPhil/PhD Students for many years.

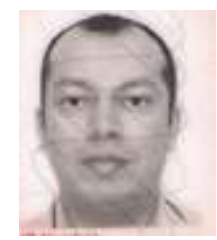

M. Kaleem Galamali is a part-time student (achieved M Phil Transfer on 28.10.2014, currently $\mathrm{PhD}$ student) at UTM under supervision of A.P. Nawaz Mohamudally. 